\title{
Labour flexibility practices in Dutch SMEs
}

\author{
Jan De Leede \\ University of Twente, Enschede, The Netherlands \\ Linda Drupsteen and Esther Schrijver \\ Windesheim Flevoland, Almere, The Netherlands \\ Anneke Goudswaard \\ Windesheim Flevoland, Almere, The Netherlands and \\ Department of Healthy Living, \\ Netherlands Organisation for Applied Scientific Research, \\ Leiden, The Netherlands \\ Nihat Dağ and Joost Van der Weide \\ Windesheim Flevoland, Almere, The Netherlands, and \\ Sarike Verbiest \\ Department of Healthy Living, \\ Netherlands Organisation for Applied Scientific Research, Leiden, The Netherlands
}

\section{Labour \\ flexibility \\ practices in \\ Dutch SMEs}

\section{1}

Received 25 February 2019

Revised 19 June 2019

19 August 2019

30 August 2019

Accepted 8 September 2019

\begin{abstract}
Purpose - The purpose of this paper is to understand how small and medium enterprises (SMEs) cope with the need for labour flexibility. Most previous studies ignore the labour flexibility practices of SMEs, especially in times of economic growth and tight labour markets.

Design/methodology/approach - A multiple case study approach is applied, with ten Dutch SMEs located in one small province with a similar labour market. A survey was executed as an intake, followed by 48 interviews with the entrepreneurs, HR and other managers and employees, and two focus groups in each company. The findings are based on an analysis of the approved case descriptions.

Findings - SMEs, like big companies, do not rely on one flexibility practice. Volume fluctuations are countered with all flexibility strategies, the mix fluctuations and the product innovations are mostly countered with flexible functions and flexible production technology. In general, the data suggest that flexibility strategies of SMEs can be characterised as ad hoc, reactive and with a short-term orientation.

Research limitations/implications - Future research should include other sectors and regions enabling to generalise the findings. Future research should have a longitudinal design to include the pathway dependencies of flexibility practices.

Practical implications - This study identifies the need to analyse flexibility demands; reduce flexibility demands before investments in flexibility practices; create production process flexibility; invest in labour flexibility practices only after the first three steps are taken; and develop basic and more advanced levels of flexible contracts, flexible functions and flexible working times.

Originality/value - This study contributes to the authors' knowledge on the use of labour flexibility practices in SMEs. In addition, it brings empirical data on how these labour flexibility practices relate to the needs for flexibility and how they relate to other sources of organisational flexibility, such as a flexible market approach and flexible production technologies. Dynamic capabilities should include the suggested operationalisation of the flexibility practices.
\end{abstract}

Keywords Qualitative, SMEs, Dynamic capabilities, Case studies, Labour flexibility

Paper type Research paper

(C) Jan De Leede, Linda Drupsteen, Esther Schrijver, Anneke Goudswaard, Nihat Dă̆, Joost Van der Weide and Sarike Verbiest. Published by Emerald Publishing Limited. This article is published under the Creative Commons Attribution (CC BY 4.0) licence. Anyone may reproduce, distribute, translate and create derivative works of this article (for both commercial and non-commercial purposes), subject to full attribution to the original publication and authors. The full terms of this licence may be seen at $\mathrm{http} / /$ creativecommons.org/licences/by/4.0/legalcode

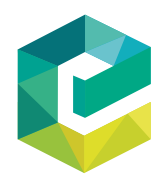

Personnel Review Vol. 49 No. 3, 2020 pp. $791-807$ Emerald Publishing Limited 0048-3486 DOI 10.1108/PR-02-2019-0086 
PR

49,3

792

\section{Introduction}

Small- and medium-sized enterprises (SMEs) are an important part of today's economies as they account for more than 99 per cent of the enterprises in the EU and for around twothirds of total employment in the EU. Although SMEs are heterogenous it is acknowledged that smaller workplaces are characterised by several key features, such as the role of the entrepreneur, the familial culture, the resource poverty and the financial structure (Welsh and White, 1981; Schmelter et al., 2010). Consequently, research on human resource management (HRM) in large organisations cannot properly explain HR practices in SMEs.

One of the challenges of SMEs is their ability to cope with demand fluctuations (Wilkinson, 1999; Matejun, 2014; Whyman and Petrescu, 2015; Kotey, 2017). Given their impact on the labour market, it is relevant to know how small enterprises deal with flexibility. Do they use the same set of labour flexibility options like large companies have (Cassell et al., 2002), e.g. agency workers and temporary employment, overtime, annualised hours and functional flexibility? Or do they rely on informal flexibility, such as a flexible attitude of employees, due to the familial nature of many small companies? To what extent is leadership within SMEs equipped to make the most effective decisions in the area of HR and labour flexibility (Mesu et al., 2013)? In the Dutch context, one of the most flexible economies of EU given the large share of part-time and flexible work arrangements and labour contracts (Hartog and Salverda, 2018), one contextual factor must be incorporated in the analysis: the tight labour market. After the crisis of 2008-2009 and some years of economic standstill, the Dutch economy has seen an economic growth since 2015 with a declining unemployment rate from 7per cent to under 4per cent in 2018 (CBS, 2018). The last couple of years, certain parts of the labour market, like ICT, construction, healthcare, technology services and high tech showed growing shortages. How do SMEs survive in this war for talent (Krishnan and Scullion, 2016)? Our research focus is on the characteristics of the labour flexibility strategies of SMEs in the Netherlands, in times of economic growth and labour shortages. The main question is "How do SMEs' labour flexibility practices fit with the need for flexibility and their other flexibility strategies, within the context of tight labour markets?"

Our theoretical framework is based on the dynamic capabilities approach (e.g. Wang and Ahmed, 2007; Pisano, 2017), rooted in the resource based view of the firm. In short, the resources of the firm deliver competitive advantage. Competitive advantage does not come from new products solely, because firms cannot survive on one-off innovations, however, it does come from the ability to develop new products (Teece et al., 1997; Teece et al., 2016). The same applies to SMEs, the need for continuation of small- and medium-sized companies is not only one-off innovations, it is also about continuously responding to changing market demands and fulfilling the needs of customers. Wang and Ahmed (2007) distinguish between adaptive, absorptive and innovative capabilities. Due to our focus on labour flexibility, we want to further develop the concept of adaptive capabilities.

Building on the dynamic capabilities approach and especially the adaptive capabilities, our central concept is the balance between the flexibility demands and the flexibility practices a company does apply (Volberda, 1996; De Leede and Goudswaard, 2008). This balance should be effective, efficient and sustainable. The firm's adaptive capabilities must offer the identification of the flexibility demands, and the effective choice within the full range of flexibility practices in order to meet the flexibility demands by the market.

\section{Theory on labour flexibility in SMEs}

The literature on HRM and labour flexibility is mainly based on evidence from large companies instead of SMEs (Cassell et al., 2002; Schmelter et al., 2010; Krishnan and Scullion, 2016; Looise et al., 1998). SMEs are small compared to large companies, small in numbers of employees and small in financial terms, like turnover and profit. Commonly, small companies are defined as having up to 49 employees on their payroll, while medium-sized companies have 50-249 employees (OECD, 2005). Apart from size, SMEs differ from large companies in 
terms of the financial structure - mainly financed by money of the owners-entrepreneurs or small loans of banks, the market area - mostly a niche, and the number of locations - usually limited and only a few establishments or sales outlets. Other dimensions, like the degree of power of the owner, the informality and the familial culture are highly debated (Ram et al., 2001). In fact, SMEs do not represent one homogenous group of companies, rather, the diversity between SMEs is large. Nevertheless, this paper will refer to it as one group while in our sampling strategy we consider the diversity of SMEs by ruling out at least two factors, i.e. sector and region, by choosing only manufacturing companies from one small province of the Netherlands operating within the same regional labour market.

What does smallness mean for a company? Small is not a little big company (Welsh and White, 1981). The assumption that small companies are just like big companies, except that they have lower sales, smaller assets and fewer employees, seems incorrect. The small size creates resource poverty, implying a need for different management capabilities. Fierce competition, environmental changes such as law and regulations and mistakes or misjudgement might have a much bigger impact on SMEs compared to large businesses. They cannot simply afford to make a big mistake in the cash flow, since liquidity is usually scarce. Therefore, they need strong generalist management skills, as they basically cannot afford all needed specialists, such as HR. Especially in SMEs, the owner-manager's values will determine how the firm will pursue the objectives of growth, diversification and internationalisation, or adopt an active or passive market behaviour.

Despite their smallness, SMEs nevertheless face the same challenges as big companies in terms of market dynamics: sales fluctuations with high peaks and deep lows, unpredictability of sales and uncertainties related to new products. Since SMEs, especially the smaller ones, usually focus on one or two market niches, they might be even more vulnerable for these kind of market dynamics. It is these challenges that led us to start our research into the capabilities of SMEs in coping with market dynamics. How do SMEs deal with the flexibility demands of the markets? Do they employ the same flexibility practices as big companies? How do they deal with new product and process innovations? Our focus is on flexibility practices related to human resources, nevertheless, it should be noted that these flexibility practices are linked with flexibility in the production process or market approach. Nevertheless, our research focus is on labour flexibility practices and not on "agile manufacturing" in general (Brown and Bessant, 2003), "responsiveness" (Upton, 1995) or on the flexible organisation (Volberda, 1996, 1998).

This paper uses the "Balance Model of Flexibility Practices" (De Leede and Goudswaard, 2008) to frame flexibility demands and flexibility practices. This model is based on three theoretical concepts: open systems, balance and dynamic capabilities. The first concept refers to the classic notion that organisational flexibility, including labour flexibility, is a response to the contextual demand. Organisations operate as open systems. Ashby (1969) already claimed in his Law of Requisite Variety that "only variety can destroy variety" (p. 110). Organisations only can survive if their abilities to respond to external demands can meet what is required from the environment. If they fail to respond to the needs and demands of customers, employees, laws and regulations, then they will disappear. In short, if there are demand fluctuations, then an organisation must respond with adequate flexibility practices to meet those fluctuations. The second concept is balance. It is a matter of balance between need and capacity, between flexibility and stability, between flexibility and planning. Planning in the meaning of a linear process of goal setting, monitoring and a rational choice in alternative routines is simply not enough to cope with complexity and uncertainty in the environment (Ansoff, 1979). Additionally, an organisation needs to have enough flexibility options to choose from and at the same time the management needs to have enough dynamic capabilities to choose timely the right options (Volberda, 1998). Dynamic capabilities are the third theoretical concept behind the Balance Model of Flexibility Practices. The dynamic capability view of the firm originated to identify the sources of competitive advantage over time, explaining why firms grow and survive 
PR

49,3

794

in turbulent operating environments (Teece, 2007). Organisations deploy dynamic capabilities to create configurations of operational capabilities (Eisenhardt and Martin, 2000; Teece, 2007). Dynamic capabilities refer to the capacity of the firm to deploy resources and processes and tacit elements embedded in processes. In a meta-analysis, Fainshmidt et al. (2016) again found evidence that dynamic capabilities are positively related to performance. More recently, dynamic capabilities are seen as referring to the choice and selection of capabilities to develop or enter new markets and the capabilities to adapt to market circumstances (Teece et al., 2016; Fainshmidt et al., 2016; Schilke et al., 2018; and especially Pisano, 2017). Many SMEs have to deal with the latter, while also facing challenges of the first. Wang and Ahmed (2007) distinguish between three types of dynamic capabilities: adaptive, absorptive and innovative capabilities. For our purpose, especially the adaptive capabilities are relevant, they refer to "the firm's ability to identify and capitalise on emerging market opportunities" (Wang and Ahmed, 2007, p. 37).

Based on these three theoretical concepts, the Balance Model of Flexibility Practices (see Figure 1), is used to analyse how SMEs deal with labour flexibility. In short, the amount of flexibility practices (Flexibility capacity) must be equal to the amount of flexibility demands (Flexibility need) in order to have competitive advantage. Furthermore, this balance should be efficient and sustainable in order to survive on the long run.

The flexibility need stems from the market demands. We distinguish between three flexibility needs:

(1) Demand volume fluctuations (the height and frequency of the volume fluctuations in the customer demands, including the extent to which these fluctuations are predictable).

(2) Demand mix fluctuations (the variations and fluctuations in customer demands in terms of the diversity of products, the degree to which customer-specific products are needed and the extent to which these fluctuations in mix are predictable).

(3) New product demand fluctuations (the possible impact of new products on the required quantities and qualities of the employees).

The flexibility capacity or the adaptive capabilities are operationalised in terms of:

(1) Market strategy (the choices a company make in terms of the number of product-market combinations and the ability to adjust the fluctuations in customers' demands (volume, mix and new product) in order to reduce the frequency and height of the fluctuations and to increase the predictability).

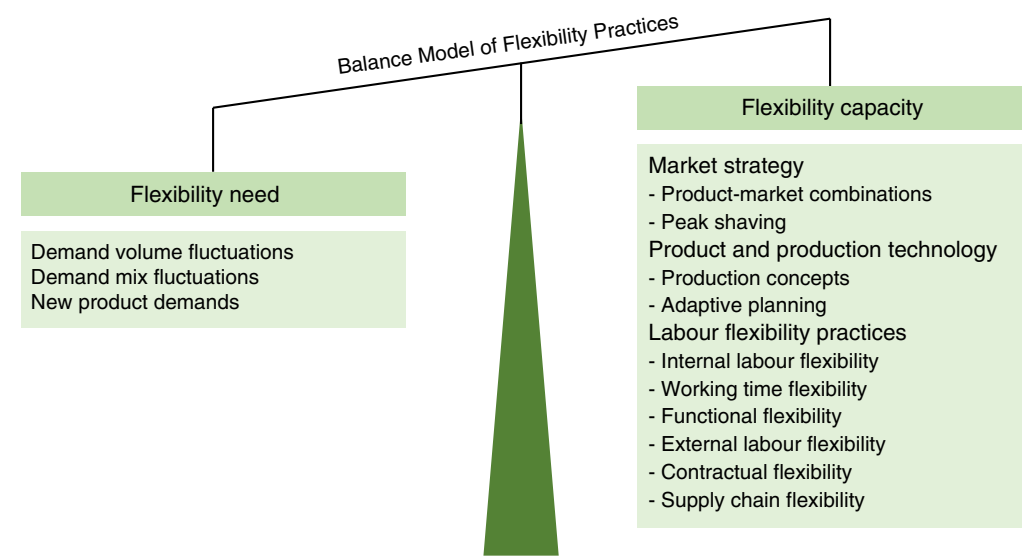

Balance model of flexibility practices

Source: Adapted from De Leede and Goudswaard (2008) 
(2) Product design and production technology (the degree to which the production processes can adapt to fluctuations in volume and mix of products and the ability of the planning function to predict the demands and to materialise it into a capacity resource planning shared with sales, purchasing, human resources and other relevant disciplines).

(3) Labour flexibility practices:

- internal flexibility practices, such as functional flexibility (the ability to cover a broad range of tasks, functions and locations) and working time flexibility (the ability to adjust the number of working hours to the required levels, using flexitime or flexible working hours, annualised hours, overtime, flexible shiftwork and flexible leave options); and

- external flexibility practices, such as flexible contracts (agency workers, fixed-term contracts, self-employed people) and supply chain flexibility (outsourcing and insourcing of work and/or workers).

Evidence for the prevalence of these flexibility practices among SMEs is limited. There are some indications that large companies make more use of all the labour flexibility practices. Wang and Heyes (2017) found that large companies use more fixed term contracts compared to SMEs. SMEs were using more permanent contracts. However, most empirical evidence is found for underlining the claim that SMEs use all kind of flexibility practices. Mesu et al. (2013) found that SMEs use both functional and working time flexibility practices. Whyman and Petrescu (2015) found also in their UK-study that SMEs use all kinds of workplace flexibility practices, such as functional, working time and contractual practices. Mihail (2004) found that Greek SMEs rely more on internal flexibility practices, such as functional and time flexibility practices. These internal practices are rooted in the informality of the small companies.

\section{Method}

A multiple case study approach was used to determine the current flexibility demands and strategies in SMEs. Ten organisations participated in the study. These SMEs are based in the province "Flevoland" in the Netherlands. Inclusion criteria were that they had between 25 and 250 employees and a clear need for flexibility due to fluctuating market demands. The minimum number of 25 employees was chosen because the flexibility and staffing needs of very small companies are different compared to companies with around 200 employees (Cardon and Stevens, 2004). The companies were recruited from local meetings and through the networks of the authors. Two researchers of the research team were responsible for collecting the data in each case company.

Data were collected in 2017-2018 through three methods: after the intake, first a survey was sent out, then three to five individual interviews were held and finally two focus groups were held. The aim of the survey was to collect information on the company's context (size, locations, tightness of labour market, turnover and absenteeism), the flexibility needs (generated by volume fluctuations, mix fluctuations and new product demands) and the flexibility practices (market strategy, production technology and labour flexibility). The survey questions were based on the Balance Model of Flexibility Practices (see Figure 1). The survey was completed by the director and if available an HR manager. The data from the survey were used to prepare the individual and focus group interviews.

Individual interviews were held in a semi-structured way to collect in-depth information on the flexibility needs and strategies. In each company, three to five interviews lasting 60-90 $\mathrm{min}$ were held: at least one with the director and two with employees. In addition, if these roles existed also the HR manager and operations manager were interviewed. The interviews with the director and other managers aimed to collect information about the company 
PR

49,3

796

(strategy, structure, culture, size and relevant developments), their flexibility needs (fluctuations in sales due to market demand volume, mix and new products), their current flexibility practices (market strategy, production process and labour flexibility practices, such as contract, time, function, location) and the need for a better match between need for and capacity of flexibility. The interviews with employees were to gain insight into their perception of flexibility needs and current practices to cope with peaks (such as overtime, the use of agency workers and multi-skilling). In total, 48 interviews were conducted and transcribed. The interviews in each company followed a semi-structured format with the same topics as the survey and the theoretical model. However, the order and focus of the topics were based on the results from the survey. For instance, if the survey revealed the absence of seasonal peaks, this was only briefly verified and not questioned in further detail.

The interviews were followed by two focus group sessions at each company, with the same participants. The first focus group was used to discuss the findings of the survey and the interviews. The current flexibility practices were summarised, leading to a discussion on the match or mismatch between the flexibility needs and practices used to cope with these demands. The outcome of the first focus group was a choice of two possible solutions to improve the match between flexibility need and capacity. The second focus group was oriented at elaborating the design of these solutions, including an implementation plan.

The data were analysed by the researchers in three rounds. First, a case description (around ten pages per company) was produced by the two researchers and checked by the company on possible mistakes. Second, the 48 interviews were transcribed, coded in several rounds and analysed within Atlas.ti. Possible co-occurrences were searched among the main variables, and between the main variables and the context variables. Third, the data were summarised in two tables highlighting the specifics per company on the flexibility need and on the flexibility capacity.

\section{Findings}

Case A

Company A has approximately 65 mechanics that provide specialised services, maintenance and training in fire safety for companies throughout the country. They developed from a company that installed and maintained a limited range of products, to a full-service company providing packages with related products and services and preventive maintenance.

Results from this company show some fluctuations between years, nonetheless, customer demands are reasonably predictable. For their main product they can predict when it must be maintained or replaced, since this is bound to formal regulations. Moreover, they mostly have returning customers. Their main challenge is that the demands peak differently depending on the region, requiring mechanics to travel or relocate frequently. Management and employees indicated to expect changes soon, since regulations change. The demands will become more unpredictable. Different types of customers call for different approaches and different skills of the company's employees. The most complicated customer-groups need to be treated proactively and are best approached by mechanics who can actively give advice about safety and not only perform the maintenance of existing equipment.

Company A uses several strategies for flexibility, covering market strategy, production technology and labour flexibility. First, they aim to limit fluctuations by spreading the maintenance work over the year and they proactively approach customers so they can plan ahead. Next, they allow mechanics to make their own planning, so they can determine the best order of the assignments and allow for extra unexpected tasks they run into. Also, they work with stock supply to make sure that every product can be installed quickly when necessary. Three labour flexibility practices are in place. First, flexible working hours, so the mechanics can plan their own work. Second, flexible functions in such a way that mechanics can cover for work in other departments and regions when necessary since they are trained 
as all-round mechanics. Third, external mechanics are sometimes hired for standardised tasks, to relieve the burden for all-round mechanics.

\section{Case B}

Company B is a logistics company that provides warehousing, transport and assembly of products for national and international customers. They employ around 50 people, of which 28 have a permanent contract. This company has different flexibility demands, depending on the type of customers: one group of products has steady demand all year round, another group has a seasonal peak at the end of the year, and one group has several unpredictable peaks throughout the year. They are understaffed at some departments, however, management assessed it too risky to hire new people, because the level of growth is not substantial enough.

Customers demand shorter delivery times and want to know the expected time of delivery. Moreover, they increasingly want to be able to decide on the delivery time. Part of the customer demand is unpredictable, and they have limited mechanisms to gain earlier insight or to spread the demand:

Our customer does not know anything. Every time we ask them to assess the volume, we do a handshake. We organize to fulfil that number of products, you cannot ask double of it, is it? And still they do. That are the dynamics of our market. If you can sell, you sell, if it is going to be a hype, then they go for it. And we have to deliver.

So, the market strategy of company B is to follow their customers, never saying no. At the time of the study, this company had little standardisation of work processes and most demands were met in an ad hoc manner. The company uses several labour flexibility practices. First, most of the employees are functionally flexible and can work for multiple clients. For some clients, specialists are needed, however, it is important that the employees can work for a wide range of customers. Second, they hire temporary workers, for instance, during summer holidays. Third, they ask employees to make overtime. However, they also emphasise that this is not the preferred measure, due to the length of some peaks: this would require employees to make long hours for many days in a row.

\section{Case C}

This production company in the food industry exists for 20 years. They produce a limited number of fresh dairy products. They have 100 employees that work in three shifts during weekdays. This company has some fluctuations over the year, but results show peaks that are never extraordinary high or very unexpected: mostly two seasonal peaks. Sometimes specific products are requested (temporary flavours of the product) which affects the volumes and require extra production capacity. Also, they have lower demand in Summer, which allows them to maintain machines or perform other activities. Their main challenge was a returning peak just before the weekend, because production was shut down in the weekend. For this reason, this company planned to change from three shifts to continuous production in five shifts, including weekends. Additionally, the planning often changes at last-minute, resulting in last-minute flexibility.

In the near future, this company expects to grow and to hire more employees. They also plan to modernise their work processes, for instance, by scanning products instead of manually counting them. Moreover, the need for innovation is increasing due to a decline in the consumption of milk, for example, by creating different and more exclusive types of fresh dairy products. It is hard to limit fluctuations, they are dependent on customer demands:

Once, we had certain flavours on the occasion of a world championship, but the Dutch team lost, and we had to give it a different name, because the order was cancelled by our customer. We had a lot of redundant products, and we could have said "you have ordered it, you should buy it". Nevertheless, it is your customer, we go for the relationship with our customer. Yet, we had a lot of redundant products. 
PR

49,3

Company $\mathrm{C}$ uses a mix of flexibility strategies, but mainly labour flexibility. The company relies on overtime (especially during the weekends) and hiring temporary workers from an agency to cover absent employees during holidays and sickness. One group temporary workers are regularly hired and second group are only hired to cover for absence and holidays. However, it is hard to find qualified people for short-term jobs, since those people could just as well find longer employment elsewhere. Furthermore, they intend to develop a core of all-round employees.

\section{Case D}

This company started 26 years ago and has grown to 70 employees. It is a manufacturing company in metal industry that creates semi-finished products. They have standard products produced on stock, as well as client specific products made on demand. Different perceptions of the fluctuations seem to exist between the management and the employees, since management thinks the volume fluctuations are not so big while employees do consider the fluctuations to be unpredictable. However, the variety of products is more challenging: they make many different products. Due to the variety of products and short process time, the main challenge of company D is to rapidly switch between products. They emphasise that the importance of short processing times will only increase in the future, unnecessary steps in the supply chain must be further reduced. Also, automatisation plays an important role in this sector, exemplified by an investment in new machinery at the time of our research.

The current flexibility strategies of this company include market strategy and labour flexibility. The client approach plays an important role: they aim to lengthen the time-to-delivery by postponing and stretching out orders when possible. Crucial is "to train and educate our clients, although we admit it does not happen very often, even if we wish". For the remaining volume and mix fluctuations, they hire temporary workers and use overtime. The temporary employees perform the simple tasks. However, much of the work requires specialists, which is why the permanent employees must work overtime. With the growth of the company, this tends to happen more often.

\section{Case E}

This manufacturing company is producing stainless steel kitchen products, mainly for catering industries and healthcare. Currently the company has around 30 employees. Their customers can choose from a wide range of standard products, available from several materials. On top of this, 20per cent of the sales comes from client specific products on request. Both management and employees indicate very high volume and mix demand fluctuations as well as high unpredictability. Orders from their main client get priority but are very unpredictable and often on short notice. Even the standard product orders are hard to predict and have short delivery times. Due to this unpredictability, the planning changes weekly or even daily and employees often must shift between tasks and products:

The big projects that are customer-specific (around 20\%), they disturb the normal planning; if these come on the wrong moment, we do suffer for weeks from it. Furthermore, the planning is based on the orders and not on the available workforce. Therefore, our employees must be flexible, if they are working on an order, they can be planned to another one; sometimes difficult to switch for people, some employees have problems with it; the work pressure is experienced as very high in our company.

The flexibility need due to product or process innovation is relatively low. The main issue for the future is to improve the relationships with the clients in order to create a more reliable forecast.

Currently, this company does not use a market strategy to control the demand fluctuations; their main client decides on the planning, and "we cannot say 'no' to our main client". There are some production process strategies. First, they keep a large stock with all possible materials to enable product mix flexibility. Second, work planning is flexible, which 
usually allows them to deliver on a very short term. Third, sometimes they can adjust delivery times meaning that some orders are postponed. Most of these strategies are scarcely used. Predominantly, company E relies on labour flexibility, typically overtime and hiring temporary workers. A third labour practice is job rotation, meaning employees are working across different departments depending on the need of these departments. Fourth, occasionally, they outsource certain jobs. However, this is not their preferred method, since third parties do not always deliver as expected, resulting in extra pressure.

\section{Labour flexibility practices in Dutch SMEs}

Case F

This construction company is part of a holding group. They have two types of business: land preparation and civil construction. The company was founded 50 years ago and has around 110 employees plus a pool of around 65 freelance workers. The work of this company is project based. The data indicate no clear peaks or lows in the demand: it is always busy. To finish their projects, the company is dependent on suppliers and co-contractors, which brings an additional challenge to their work planning:

We try to look better to the forecast, in order to have the products when needed. However, we are dependent on the delivery times of suppliers. I think we cannot do much better. Yes, you might say to procure much earlier, but that is not always possible. You have to start the work within five days upon acceptance of the order. Sometimes, it cannot be done else.

The main challenge is to balance the workforce of both specialists and all-round workers. By providing specialist services, this company distinguishes itself from others but at the same time it requires employees that can work on all types of projects. This means that the company needs to balance the competences of their workforce to match the market demand, while also satisfying the need to develop the employees. Furthermore, the company expects to grow while some experienced all-round employees will retire. It is therefore important to recruit new employees, which turns out to be difficult in the current tight labour market. Little need for flexibility stems from product and process innovation.

Company $\mathrm{F}$ has a mix of flexibility strategies. Currently projects are acquired as early as possible, to enable to plan and balance the demand fluctuation as much as possible. Furthermore, they employ peak shaving by production process flexibility via thorough planning and preparation of projects. The labour flexibility strategy relies on external workers. An important resource for flexibility is a group of freelance workers that is frequently used for projects. These freelancers are hired both for specialized tasks as well as for routine tasks. Also, they vary the amount of outsourcing to other construction companies. Finally, their own workers, specifically the experienced specialists, can rotate across many tasks.

Case $G$

This innovative food processing company founded over 75 years ago and is specialised in optimising preservation and processing techniques of agricultural products. They have around 160 employees, who work at two locations. In the near future, they plan to develop intelligent information technology that enables them to collect and analyse relevant data for the production process, in order to improve products and reduce energy use.

The data indicate two clear peaks in volume throughout the year: in summer (harvest time and holidays) and before Christmas holidays (maintenance). Nevertheless, the main challenge for company $\mathrm{G}$ is the number and nature of mix fluctuations: many different products, many customer-specific specials and all fresh crops have limited preservability (thus having a short time to delivery). The implication is to rapidly change from one product to another, requiring changes in production process, such as machine settings, resources and workflow activities. An additional challenge is that this company cannot find enough 
PR

49,3

800

qualified employees. Next to ongoing technological development, company $\mathrm{G}$ is becoming internationally oriented, targeted at other time zones to reduce the seasonal dependency.

Company G uses several flexibility strategies. There is currently no market strategy to reduce market demand fluctuations, except for the internationalisation. The company uses production process flexibility: work processes are standardized wherever possible to reduce inefficiency and the planning systems allow for better forecasts. The main flexibility capacity is found in labour, especially in external flexibility such as supply chain flexibility (outsourcing specific parts of the work, after which the semi-finished products are finished within the company) and contractual flexibility like hiring temporary workers and freelancers. They also have working time flexibility, mainly overtime. To some extent functional flexibility is implemented, with a limited group of workers that can rotate over jobs. Unfortunately, most departments peak at the same time, thus the rotation does not help in coping with these peaks. In addition, these all-rounders work most overtime and have high work pressure. As a result, there is too much overtime, according to employees:

The risk of all these long hours is burnout; I am concerned about these people." "I am fed up with these overtime hours". "Production suffers from limited workforce capacity. Then they 'just' make use of overtime. Although absenteeism is still low, it is not the right thing to do.

\section{Case $H$}

Company $\mathrm{H}$ develops, produces and installs products for the construction industry. They are an independent company as part of the same holding company as company I. This company has 63 employees (mainly in production and installation service), of which 22 have a temporary contract. Most of the products, around 75 per cent, are made in bulk orders, which is continuous production; the other 25 per cent are client specific orders.

There are no large volume fluctuations in demand for the production department. However, the installation service department must cope with high volume fluctuations. The weather strongly influences these variations since much of the installation work is done outside and cannot continue in severe rain, storm or low temperatures. Another influencer are short-term customer demands, often resulting in last minute changes in the work planning. Company $\mathrm{H}$ works mostly as part of a contractor chain, they depend on the planning of external parties, which can be very unpredictable:

The biggest obstacle is the planning, that should be improved. The employees experience little continuity, and that they have to work on many different products simultaneously. To tell the truth, you want to finish the job yourself.

A complicating issue is that the sales department sometimes adds jobs to the planning without consultation, thus creating an unpredictable increase in work pressure for the mechanics. Again, this is the result of the attitude of "making whatever the customer asks for".

Company $\mathrm{H}$ uses some flexibility practices, especially production technology and labour flexibility. They do not make use of a market strategy to balance out the demand fluctuation. In the production department, the main strategy is to work ahead when they can, thus creating a stock. In the installation service department, the main strategy according to the employees is "to simply work harder". The installation department uses an elementary form of annualised hours, meaning that extra hours are registered and could - in theory - be compensated later with days off. Since it is seldomly quiet it is difficult to compensate for these extra hours. A second strategy is to split up the installation mechanics that normally work in couples, while providing them assistance from a production worker. They prefer to work with "own" employees over hiring freelance workers because this allows them to guarantee the quality of the product and to maximise revenue. 
Case I

This company specializes in indoor climate control. They install, maintain and repair air control systems. Nowadays they are part of a holding with four independent subcompanies (including case $\mathrm{H}$ ). This company has four departments and a separate service department for repair, maintenance and installation. They have around 75 employees, for some specific smaller jobs temporary workers are hired.

The volume demand fluctuations are mostly predictable in this company: they know what orders will come and how much work this will be, but sometimes the timing may change. Only incidentally emergencies occur in which instantly the installation of a client needs to be replaced. During Summer and Autumn, they have more work than in Winter. The company has several different products and sometime new products are added, but employees indicate that this hardly affects their work. Although the demand is quite predictable, management notices the need for more flexibility to respond quickly to demands and emergency requests:

The 24/7 service requests of customers do increase, including much more customer-specific requests. In addition, the urgency of the problem solving is increasing. The planning should fit with our workforce capacity, if it is not possible, we must sell 'no' to the client. And, the client with the biggest noise will be serviced first.

The need for flexibility due to product and process innovation is relatively low.

Company I uses a mix of flexibility strategies. At the time of the interviews, they started with peak shaving by even out the work across all months, for instance, by urging the clients to plan the work in the first quartile of the year and giving a discount in the winter months. Furthermore, the planning is partly based on minimum stock levels, but these are flexible, so in quiet months they can produce something extra to stock. The most important source for flexibility is labour: multi-skilled employees that can be planned on different products and many clients. The specialists are supported by other mechanics if needed during peak periods. In addition, they use annualised hours, only for service department and to a limited extent because of their view that long hours are not effective and sustainable. Incidentally they hire agency workers for the simple tasks.

\section{Case J}

Company $\mathrm{J}$ is a food processing company working on cultivation and innovation of potato varieties, including packing, processing and exporting potatoes and potato products. They have over 160 employees. The two largest departments work on sorting and peeling of the potatoes.

The data show high volume fluctuations in demand. The overall peak season is in winter, but they also have a peak in May. Throughout the year customer demands are unpredictable. The planning changes daily, even on the day itself. In addition, the mix fluctuations are high. They have many varieties of products, all with a limited conservation. Their main challenge is not so much the unpredictability of the customers, rather the unpredictability of the potatoes. Dependent on the harvest, they never know how much will be delivered of a variety and how much will be suitable for processing. Also, only one variety at a time can be processed in the production facility. Another challenge is the rather long training time of employees, around four to six months. Company $\mathrm{J}$ is continuously innovating products and new varieties lead to new processed products. Also, they plan to automate parts of the process, to be more efficient using less and less skilled employees:

I need to have very flexible people. A lot of people are already flexible and to some extent multiskilled, so if it is very busy, we can put people from one job to a more difficult job. The disadvantage is that most processes are complex, so you need three, four months to perform without mistakes. If a batch is running incorrect, it is 10.000 euro or more. So, if it is very busy, we must be careful in rotating our people.

\section{Labour flexibility practices in Dutch SMEs}


PR

49,3

802

Company J mainly uses labour flexibility strategies to cope with demand fluctuations. Market strategies, such as influencing customers, is simply nearly possible. Also, advanced planning methods are not considered since they work with fresh products: they know which potato will be delivered, but they cannot know how much and to what extent these potatoes are suitable for processing. To cope with the fluctuations, the company uses three labour flexibility practices. First, they hire temporary workers, just for the easy tasks, taking off most pressure during peaks. Second, the working hours of regular employees are stretched to make up for changes and delays that arise during the day. It comes down to working longer hours, which are compensated by money and time. Third, there is a small evening crew specifically to catch up with possible delays.

\section{Discussion}

After discussing the flexibility needs and flexibility practices, we summarise the theory, research and practice implications of this study.

\section{Flexibility needs}

To describe the flexibility needs in the participating SMEs, we analysed the perceived fluctuations due to volume, mix and product innovations (see Table I). In relation to volume fluctuation, three aspects seem to be relevant: the frequency and the amplitude of fluctuations as well as the perceived predictability of the fluctuations. A distinctive issue is how these SMEs can predict the frequency and amplitude of the fluctuations. For many of the participating SMEs, the overall level of predictability of the demand is perceived as low to moderate. As an example: seasonal peaks can be very high but predictable and therefore adequately be dealt with (such as in company C). However, if similar peaks occur very unexpectedly it may be more difficult to cope with (as is showed by company B with customers not able to predict what might become a hype and therefore they cannot predict how much transport and services are needed). Another example of the impact of predictability is the difference between companies A and $\mathrm{E}$. In company $\mathrm{A}$, the market demands fluctuate constantly - they have a high frequency. Because the peaks are not too high and because they are predictable, it is easier to follow the fluctuations with a good mix of flexibility capabilities. However, market demands that fluctuate during all seasons in combination with the inability to predict the fluctuations (company E) leads to a different flexibility need, with another set of flexibility capabilities.

Two important aspects relate to mix fluctuation. It is the impact of the width of the product range and again the predictability. Many SMEs operate in markets that call for a large variation of products and customer-specific adjustments. The width of the product range relates to the number of markets a company is in and to the number of variations the customers demand for. Especially if the variations and the customer-specific adjustments are significant in terms of different skills needed (see company E) the impact of demand mix fluctuations is huge. Like volume fluctuation, predictability seems to be a key determinant for flexibility need due to demand mix fluctuation. The impact of unexpected changes in required product variations might be high in terms of required people, materials and other resources. The work planning must be flexible because different products may require other tasks, machine settings or people (companies E and F). Therefore, it seems to be relevant for SMEs to deal with product variation and choose for the right number of products or markets in which a company operates and the extent (and frequency) to which they customise their products for the client.

The fluctuations due to product or process innovation seem to be rather limited. Here one aspect seems to be important: task complexity (Haerem et al., 2015). Only to some extent product innovation leads towards a flexibility need, for instance in companies A and $\mathrm{G}$ whose investments in new technology require better skilled employees. Due to a higher task 


\begin{tabular}{|c|c|c|c|c|c|c|c|}
\hline & & & Capacity & for flexibility & & & $\begin{array}{l}\text { Labour } \\
\text { flexibility }\end{array}$ \\
\hline & approach & production & Flexible worktimes & Flexible functions & cont & & $\mathrm{D}$ \\
\hline Company A & Moderate & Low & $\begin{array}{l}\text { Mostly basic } \\
\text { (overtime) }\end{array}$ & $\begin{array}{l}\text { High (junior- } \\
\text { senior + all-round) }\end{array}$ & $\begin{array}{l}\text { Moderate } \\
\text { (agency } \\
\text { workers) }\end{array}$ & Low & 803 \\
\hline Company B & Low & Low & $\begin{array}{l}\text { Mostly basic } \\
\text { (overtime+ flex. } \\
\text { time) }\end{array}$ & $\begin{array}{l}\text { High (now } 50 \% \\
\text { all-round, must } \\
\text { increase) }\end{array}$ & $\begin{array}{l}\text { Moderate } \\
\text { (agency } \\
\text { workers) }\end{array}$ & Low & \\
\hline Company C & Low & Low & $\begin{array}{l}\text { Mostly basic } \\
\text { (overtime }+3-5 \\
\text { shifts) }\end{array}$ & $\begin{array}{l}\text { Limited (must } \\
\text { increase) }\end{array}$ & $\begin{array}{l}\text { High (agency } \\
\text { workers) }\end{array}$ & Low & \\
\hline Company D & Moderate & Moderate & $\begin{array}{l}\text { Mostly basic } \\
\text { (overtime) }\end{array}$ & $\begin{array}{l}\text { Moderate (must } \\
\text { increase) }\end{array}$ & $\begin{array}{l}\text { High (agency } \\
\text { workers) }\end{array}$ & Low & \\
\hline Company E & Low & $\begin{array}{l}\text { Low- } \\
\text { moderate }\end{array}$ & $\begin{array}{l}\text { High, mostly basic } \\
\text { (overtime) }\end{array}$ & $\begin{array}{l}\text { Moderate (job } \\
\text { rotation; must } \\
\text { increase) }\end{array}$ & $\begin{array}{l}\text { high (agency } \\
\text { workers) }\end{array}$ & Low & \\
\hline Company F & $\begin{array}{l}\text { Low- } \\
\text { moderate }\end{array}$ & Low & Low & $\begin{array}{l}\text { Moderate } \\
\text { (employable } \\
\text { within own } \\
\text { department) }\end{array}$ & $\begin{array}{l}\text { High (free- } \\
\text { lance) }\end{array}$ & $\begin{array}{l}\text { Moderate- } \\
\text { high (e.g. } \\
\text { outsourcing) }\end{array}$ & \\
\hline Company G & Low & Moderate & $\begin{array}{l}\text { Mostly basic } \\
\text { (overtime) }\end{array}$ & $\begin{array}{l}\text { Moderate (job } \\
\text { rotation for some } \\
\text { employees) }\end{array}$ & $\begin{array}{l}\text { Moderate } \\
\text { (agency } \\
\text { workers) }\end{array}$ & $\begin{array}{l}\text { Moderate } \\
\text { (outsourcing) }\end{array}$ & \\
\hline Company $\mathrm{H}$ & Low & $\begin{array}{l}\text { Moderate } \\
\text { (stock) }\end{array}$ & $\begin{array}{l}\text { Moderate } \\
\text { (annualised hours) }\end{array}$ & $\begin{array}{l}\text { Moderate (job } \\
\text { rotation for some } \\
\text { employees) }\end{array}$ & Low & Low & \\
\hline Company I & Moderate & $\begin{array}{l}\text { Low } \\
\text { (stock) }\end{array}$ & $\begin{array}{l}\text { Moderate (overtime } \\
+ \text { annualised hours) }\end{array}$ & $\begin{array}{l}\text { High (multi-skilled } \\
\text { if possible) }\end{array}$ & $\begin{array}{l}\text { Low } \\
\text { (incidentally } \\
\text { agency } \\
\text { workers) }\end{array}$ & Low & \\
\hline Company J & Low & High & $\begin{array}{l}\text { High (overtime + } \\
\text { annualised hours }+ \\
\text { flexible hours) }\end{array}$ & $\begin{array}{l}\text { Moderate (job } \\
\text { rotation) }\end{array}$ & $\begin{array}{l}\text { High (agency } \\
\text { workers) }\end{array}$ & Low & $\begin{array}{r}\text { Table I. } \\
\text { Summary of the need } \\
\text { for flexibility for }\end{array}$ \\
\hline Source: $\mathrm{Co}$ & mplied by & authors & & & & & \\
\hline
\end{tabular}

complexity of developing and producing the new products or using the new equipment, multi-skilling and collaboration between several disciplines is therefore an important aspect. However, new technology can also lead towards a lower task complexity, such as in company J, where new production technology result in more simple jobs that are easier to staff in the tight labour market. For them, this process innovation served as a source to cope with flexibility need.

\section{Flexibility practices}

The flexibility practices deployed by the SMEs participating in this study in response to the market demands can be divided into three strategies: the market strategy, product and production technology, and labour flexibility practices. Table II summarises the flexibility practices, leading to four observations. The first observation is that all SMEs use almost all types of flexibility strategies, although the market approach and the supply chain are less used. Nevertheless, we may conclude that all companies try to develop a mix of flexibility practices. They are not relying on one practice only. 
PR

49,3

\begin{tabular}{|c|c|c|c|c|}
\hline & Volume fluctuation & Mix fluctuation & $\begin{array}{l}\text { Need for flexibility } \\
\text { New product demands } \\
\text { fluctuation }\end{array}$ & Level of unpredictability \\
\hline Company A & Low & Low, increasing & Low, increasing & Moderate \\
\hline Company B & High & High & Low & Moderate, some products high \\
\hline Company $\mathrm{C}$ & Moderate & Low & Moderate & Moderate \\
\hline Company D & Moderate & High & Moderate & Moderate \\
\hline Company E & High & High & Low & High \\
\hline Company $\mathrm{F}$ & Low & High & Low & Moderate \\
\hline Company $\mathrm{G}$ & Moderate & High & Moderate & Moderate \\
\hline Company $\mathrm{H}$ & Moderate & Moderate & Low-moderate & High \\
\hline Company I & Moderate & Moderate & Low-moderate & Low \\
\hline Company J & High & Moderate & Moderate & High \\
\hline
\end{tabular}

The second observation is that labour flexibility practices, such as flexible contracts, flexible functions and flexible working times, are the most frequently applied strategy, followed by production process and finally the market approach practices. The companies do not often attempt to influence customers' demands as part of their market strategy. Unanimously, the entrepreneurs state that they take every sales opportunity: saying no to the customer is a "no-go". Only after saying yes to new orders they start to consider how to make it possible within the organisation, often resulting in a sudden increased demand. This strategy is what makes their business successful and fuels their growth. The companies do have some flexibility as a result of their market strategy. By planning with a long forecast (such as F and G) or by being able to spread work over time (such as case A and I), fluctuations may be balanced.

The third observation is about the rather limited use of production process practices. Working with stock supply is only possible for some companies, depending on product characteristics. Our data show that advanced levels of capacity planning, resource planning and the resulting flexibility of planning methods are not a commonplace in SMEs. Sometimes it is due to the informal character of the SME, the size of the company relative to the costs associated with advanced planning tools, sometimes to the intrinsic nature of following all client demands.

The fourth observation is a consequence of the second one: due to the inclination of not saying "no" to customers, most flexibility strategies can be characterised as ad hoc. Most companies (eight out of ten) rely on overtime. An advanced method to deal with long hours, such as annualised hours is only used to a limited extent (case $\mathrm{H}$, I and J). Also, the use of agency workers can be viewed as an example of $a d$ hoc. Although the data found that most companies used functional flexibility such as multi-skilling, it was rather in the premature stage of limited job-rotation. Only some companies used more advanced HR practices to develop their employees in a structured way using career paths, training plans and skill development schemes. Almost all companies indicated their intention to develop in this direction. Most companies acknowledge this ad hoc character, they recognise the need to transform it into a more strategic and sustainable approach.

\section{Theoretical implications}

Most frequently used are flexible functions, closely followed by flexible working times and flexible contracts. This finding is in line with other literature suggesting that SMEs are using every type of labour flexibility, relying most on internal flexibility practices, such as time and function (Mihail, 2004; Mesu et al., 2013; Whyman and Petrescu, 2015). Compared to large companies, SMEs do apply the same set of both internal and external labour 
flexibility practices. The differences might be that SMEs follow a more ad hoc strategy and that they apply these practices in a more premature way in terms of the professionalisation of the design and use of the practices. The implication for theory on dynamic capabilities might be the inclusion of company size as an important factor in assessing the maturity of the set of flexibility practices (Arend, 2014).

Our list of flexibility practices within SMEs suggests sharper operationalisations of the concept of adaptive capabilities (Wang and Ahmed, 2007): market strategy, production process and labour flexibility practices, including the proposed practices within each category. The implication is that our operationalisations may function as a bridge between operational and dynamic capabilities, for which many authors find it difficult to draw a clear line between the two (Helfat and Winter, 2011; Arend, 2014; Wilden et al., 2016).

\section{Research implications and limitations}

This study also has its limitations. One is the limited generalisation across SMEs due to its design as a multiple case study. Ten SMEs participated in the study, all located in one geographical area. They experienced the same labour market and were private owned, implying no information is obtained with other labour market characteristics nor from service and public organisations. Further research should be designed covering multiple industries and regions, using both qualitative and quantitative methods to generalise our findings across sectors, labour markets and geographical areas. A second limitation is the restricted longitudinal nature of our study with observations at only two moments in time. A longitudinal design with a process approach (Dawson, 2019) with more observation points could have revealed more of the dynamic nature of flexibility needs and flexibility practices, as well as the interaction between the different flexibility practices. For instance, it is valuable to get a better understanding of the pathway dependency: once managers have chosen to rely on external flexibility, it has its implications for the room to choose for internal flexibility practices. Within our design, we could only ask for this kind of relations and not observe them over time.

\section{Practical implications}

The following steps are recommended to achieve a more sustainable, pro-active labour flexibility strategy of SMEs moving beyond an ad hoc and short-term oriented flexibility strategy. First, analyse the needs for flexibility: the need for flexibility implies an assessment of the frequency, amplitude and predictability of volume fluctuations, width of product range and predictability of mix fluctuations, and impact of product innovation on task complexity. Second, reduce flexibility needs: an advanced market approach entails close customer interaction to enable peak shaving and a careful selection of market segments. Before investing in flexibility practices, it is better to reduce the need for flexibility. Third, create production process flexibility: a redesign of operational processes to create workplaces for low-, medium- and high-skilled employees and an investment in flexible production technologies enables higher flexibility. Fourth, invest in labour flexibility practices: only after the first three steps SMEs must develop labour flexibility practices. Fifth, develop advanced levels of labour flexibility. Beyond basic labour flexibility practices (such as overtime and agency workers) SMEs can develop more advanced levels of flexible contracts (inhouse-agency workers, free lancers, outsourcing and other supply chain solutions), flexible functions (job rotations, multi-skilling) and flexible working times (flexitime, flexible shift patterns, annualised hours).

\section{Conclusion}

SMEs, like big companies, do not rely on one flexibility practice. Each type of flexibility need (volume, mix, product innovation) is countered with a mix of flexibility practices. Volume fluctuations are countered with all flexibility strategies (market strategy, production process 
PR

49,3

\section{6}

and labour flexibility), the mix fluctuations and the product innovations are mostly countered with flexible functions and flexible production technology. In general, the data suggest that overall the flexibility strategies can be characterised as ad hoc short-term solutions. Caused by the tight labour market, we observed a willingness of the SMEs to invest in a better and more sustainable match between the needs for flexibility and their adaptive capabilities, such as better aligned and more professional work processes.

\section{References}

Ansoff, H.I. (1979), "The changing shape of the strategic problem”, Journal of General Management, Vol. 4 No. 4, pp. $42-59$.

Arend, R.J. (2014), "Entrepreneurship and dynamic capabilities: how firm age and size affect the 'capability enhancement-SME performance' relationship”, Small Business Economics, Vol. 42 No. 1 , pp. 33-57.

Ashby, W.R. (1969), "Self regulation and requisite variety", in Emery, F.E. (Ed.), Systems Thinking: Selected Readings, Penguin Books, Harmondsworth, pp. 105-124.

Brown, S. and Bessant, J. (2003), "The manufacturing strategy-capabilities links in mass customization and agile manufacturing - an exploratory study", International Journal of Productions and Operations Management, Vol. 23 No. 7, pp. 707-730.

Cardon, M.S. and Stevens, C. (2004), "Managing human resources in small organizations: What do we know?", Human Resource Management Review, Vol. 14 No. 3, pp. 295-323.

Cassell, C., Nadin, S., Gray, M. and Clegg, C. (2002), "Exploring human resource management practices in small and medium sized enterprises", Personnel Review, Vol. 31 No. 6, pp. 671-692.

CBS (2018), "Statline, Arbeidsdeelname en werkloosheid per maand", available at: https://opendata.cbs. nl/statline/

Dawson, P. (2019), Reshaping Change; A Processual Perspective, 2nd ed., Routledge, New York, NY.

De Leede, J. and Goudswaard, A. (2008), "Flexibele organisatie: Nieuwe inzichten over de afstemming tussen strategie, personeel en proces", in Dhondt, S. and Vaas, F. (Eds), Waardevol werk: Van arbeidskwaliteit naar sociale innovatie, Lemma, Den Haag, pp. 216-230.

Eisenhardt, K. and Martin, J. (2000), "Dynamic capabilities: what are they?", Strategic Management Journal, Vol. 21 Nos 10/11, pp. 1105-1121.

Fainshmidt, S., Pezeshkan, A., Lance Frazier, M., Nair, A. and Markowski, E. (2016), "Dynamic capabilities and organizational performance: a meta-analytic evaluation and extension", Journal of Management Studies, Vol. 53 No. 8, pp. 1348-1380.

Haerem, T., Pentland, B.T. and Miller, K.D. (2015), "Task complexity: extending a core concept", Academy of Management Review, Vol. 40 No. 3, pp. 446-460.

Hartog, J. and Salverda, W. (2018), "The labor market in the Netherlands, 2001-2016”, IZA World of Labor, No. 418, pp. 1-12.

Helfat, C.E. and Winter, S.G. (2011), "Untangling dynamic and operational capabilities: strategy for the (n)ever-changing world”, Strategic Management Journal, Vol. 32 No. 11, pp. 1243-1250.

Kotey, B.A. (2017), "Flexible working arrangements and strategic positions in SMEs", Personnel Review, Vol. 46 No. 2, pp. 355-370.

Krishnan, T.N. and Scullion, H. (2016), "Talent management and dynamic view of talent in small and medium enterprises”, Human Resource Management Review, Vol. 27 No. 3, pp. 431-441.

Looise, J.C., van Riemsdijk, M. and de Lange, F. (1998), "Company labour flexibility strategies in The Netherlands: an institutional perspective", Employee Relations, Vol. 20 No. 5, pp. 461-482.

Matejun, M. (2014), "The role of flexibility in building the competitiveness of small and medium enterprises", Management, Vol. 18 No. 1, pp. 154-168.

Mesu, J., Van Riemsdijk, M.J. and Sanders, K. (2013), "Labour flexibility in SMEs: the impact of leadership”, Employee Relations, Vol. 35 No. 2, pp. 120-138. 
Mihail, D.M. (2004), "Labour flexibility in Greek SMEs”, Personnel Review, Vol. 33 No. 5, pp. 549-560. OECD (2005), SME and Entrepreneurship Outlook: 2005, OECD, Paris.

Pisano, G.P. (2017), "Toward a prescriptive theory of dynamic capabilities: connecting strategic choice, learning, and competition", Industrial and Corporate Change, Vol. 26 No. 5, pp. 747-762.

Ram, M., Edwards, P., Gilman, M. and Arrowsmith, J. (2001), "The dynamics of informality: employment relations in small firms and the effects of regulatory change", Work, Employment and Society, Vol. 15 No. 4, pp. 845-861.

Schilke, O., Hu, S. and Helfat, C.E. (2018), "Quo vadis, dynamic capabilities? A content-analytic review of the current state of knowledge and recommendations for future research", Academy of Management Annals, Vol. 12 No. 1, pp. 390-439.

Schmelter, R., Mauer, R., Börsch, C. and Brettel, M. (2010), "Boosting corporate entrepreneurship through HRM practices: evidence from German SMEs", Human Resource Management, Vol. 49 No. 4, pp. 715-741.

Teece, D. (2007), "Explicating dynamic capabilities: the nature and microfoundations of (sustainable) enterprise performance", Strategic Management Journal, Vol. 28 No. 13, pp. 1319-1350.

Teece, D., Peteraf, M. and Leih, S. (2016), "Dynamic capabilities and organizational agility: risk, uncertainty, and strategy in the innovation economy", California Management Review, Vol. 58 No. 4, pp. 13-35.

Teece, D.J., Pisano, G. and Shuen, A. (1997), "Dynamic capabilities and strategic management", Strategic Management Journal, Vol. 18 No. 7, pp. 509-533.

Upton, D.M. (1995), “What really makes factories flexible?”, Harvard Business Review, Vol. 73 No. 4, pp. 74-84.

Volberda, H.W. (1996), "Toward the flexible firm, how to remain vital in hypercompetitive environments", Organization Science, Vol. 7 No. 4, pp. 359-374.

Volberda, H.W. (1998), Building the Flexible Firm: How to Remain Competitive, Oxford University Press, Oxford.

Wang, C.L. and Ahmed, P.K. (2007), "Dynamic capabilities: a review and research agenda", International Journal of Management Reviews, Vol. 9 No. 1, pp. 31-51.

Wang, W. and Heyes, J. (2017), "Flexibility, labourretention and productivity in the EU", The International Journal of Human Resource Management, pp. 1-21, doi: 10.1080/ 09585192.2016.1277370.

Welsh, J.A. and White, J.F. (1981), "A small business is not a little big business”, Harvard Business Review, Vol. 59 No. 4, pp. 18-32.

Whyman, P.B. and Petrescu, A.I. (2015), "Workplace flexibility practices in SMEs: relationship with performance via redundancies, absenteeism, and financial turnover", Journal of Small Business Management, Vol. 53 No. 4, pp. 1097-1126.

Wilden, R., Devinney, T.M. and Dowling, G.R. (2016), "The architecture of dynamic capability research", The Academy of Management Annals, Vol. 10 No. 1, pp. 997-1076.

Wilkinson, A. (1999), “Employment relations in SMEs”, Employee Relations, Vol. 21 No. 3, pp. 206-217.

\section{Corresponding author}

Jan De Leede can be contacted at: j.deleede@utwente.nl

For instructions on how to order reprints of this article, please visit our website:

www.emeraldgrouppublishing.com/licensing/reprints.htm

Or contact us for further details: permissions@emeraldinsight.com 